\title{
GAMBARAN KUALITAS HIDUP PASIEN CEDERA KEPALA PASCA OPERASI PERIODE JANUARI 2012 - DESEMBER 2013 DI RSUP PROF. DR. R. D. KANDOU MANADO
}

\author{
${ }^{1}$ Patrick Zwingly \\ ${ }^{2}$ Maximillian Ch. Oley \\ ${ }^{2}$ H. P. Limpeleh \\ ${ }^{1}$ Kandidat Skripsi Fakultas Kedokteran Universitas Sam Ratulangi Manado \\ ${ }^{2}$ Bagian/SMF Fakultas Kedokteran Universitas Sam Ratulangi Manado \\ Email: patrickmawu93@gmail.com
}

\begin{abstract}
Traumatic brain injury is a major global problem. Global incident average in urban areas ranged from 108 to 332 new cases admitted to the hospital per 100,000 population per year. About $39 \%$ of patients with severe brain trauma died due to injuries, and $60 \%$ had low Glasgow Outcome Scale (GCS). Neurosurgical surgery decreased the incidence of death and injury due to head trauma from 72 to $25 \%$. However, patients still show significant disability after completion of therapy. Disability could manifest in the form of physical, mental, and/or behavior disability. This was a descriptive study with a cross-sectional design by using a questionnaire. This study aimed to obtain the quality of life of patients with head injury in post-operative period from January 2012 December 31, 2013 in Prof. R. D. Kandou Hopital Manado. The results showed that most respondents were male (61.3\%), aged 11-20 years (48.6\%). Most respondents lived at Malalayang (19.4\%). The most frequent head injuries were mild head injuries $(74.2 \%)$. The final states of the patients (GOS) were: good recovery $58.1 \%$ and moderate disability $41.9 \%$. Patients with GCS mild, moderate, or good recovery disability were $3.2 \%$ each. Patients with GCS were mostly good recovery (48.4\%). Most patients with severe GCS experienced moderate disability (12.9\%). Characteristics of patient satisfaction were satisfied 54.8\% and not satisfied $45.2 \%$. Relationship of satisfaction level with GOS was as follows: most satisfied patients had good recovery (35.5\%), where as most not-satisfied patients had moderate disability (29.0\%).
\end{abstract}

Keywords: head injury, post craniotomy, patient satisfaction

\begin{abstract}
Abstrak: Kerusakan otak traumatik merupakan masalah global utama. Insiden rata-rata di perkotaan secara global berkisar dari 108 sampai 332 kasus baru yang masuk rumah sakit per 100.000 populasi per tahun. Rata-rata 39\% pasien-pasien dengan trauma otak berat meninggal karena cedera, dan 60\% memiliki Glasgow Outcome Scale (GCS) yang rendah. Tindakan operasi bedah saraf menurunkan insiden kematian dan cedera akibat trauma kepala dari 72 sampai 25\%. Meski demikian, pasien-pasien tetap menunjukkan kecacatan yang nyata sesudah menyelesaikan terapi, baik berupa cacat fisik, mental, dan/atau perilaku. Penelitian ini bertujuan untuk melihat gambaran kualitas hidup pasien cedera kepala pasca operasi periode Januari 2012-Desember 2013 di RSUP. Prof. Dr. R. D. Kandou Manado. Hasil penelitian menunjukkan responden terbanyak ialah laki-laki (61,3\%), usia terbanyak 11-20 tahun (48,6\%), alamat responden terbanyak di Malalayang (19,4\%). Cedera kepala terbanyak ialah cedera kepala sedang sebesar 74,2\%. Keadaan akhir pasien (GOS), good recovery sebesar 58,1\%, sedangkan moderate disability $41,9 \%$. Pasien dengan GCS ringan, moderate dissability dan good recovery masing-masing sebesar 3,2\%. Pasien dengan GCS sedang paling banyak good recovery yaitu 48,4\%. Pasien dengan GCS berat paling banyak mengalami moderate dissability yaitu $12,9 \%$. Karakteristik kepuasan pasien diperoleh puas sebesar 54,8\% sedangkan yang tidak puas 45,2\%. Hubungan tingkat kepuasan dengan GOS, yang puas ter banyak pasien yang good recovery yaitu $35,5 \%$, sedangkan yang tidak puas terbanyak moderate dissability yaitu 29,0\%.
\end{abstract}

Kata kunci: cedera kepala, pasca kraniotomi, kepuasan pasien. 
Kerusakan otak traumatik adalah masalah global utama. Insiden rata-rata di perkotaan secara global berkisar dari 108 sampai 332 kasus baru yang masuk rumah sakit per 100.000 populasi per tahun. Rata-rata 39\% pasien-pasien dengan trauma otak berat meninggal karena cedera, dan 60\% memiliki GCS (Glasgow Outcome Scale)yang rendah. Insiden cedera otak traumatik meningkat di negara-negara dengan penghasilan rendah dan menengah karena peningkatan transportasi yang meningkatkan kecelakaan, dan usia muda paling sering menjadi korban. ${ }^{1}$ Tingkat kecelakaan lalulintas di Sulawesi Utara pada tahun 2012 sebanyak 1.269 kasus, dengan korban meninggal 292, luka berat sebanyak 683 orang dan luka ringan 1.076 orang.Di Kota Manado menurut Polresta Manado, kecelakaan lalulintas terjadi sebanyak 414 kasus dengan korban meninggal 73 orang, luka berat 146 orang, ringan 375 orang, dengan kerugian ditaksir sebesar 1,798 miliar rupiah. ${ }^{2}$

Cedera kepala telah menyebabkan banyak kematian dan cacat pada usia kurang dari 50 tahun. Otak bisa mengalami cedera meskipun tidak terdapat luka yang menembus tulang tengkorak. Berbagai cedera bisa disebabkan oleh percepatan mendadak yang memungkinkan terjadinya benturan atau karena perlambatan mendadak yang terjadi jika kepala membentur objek yang tidak bergerak. Kerusakan otak bisa terjadi pada titik benturan dan pada sisi yang berlawanan.,

Tindakan operasi bedah saraf seperti kraniotomi merupakan proses medis lanjut yang didesain untuk menurunkan insiden kematian dan cedera akibat trauma kepala. Kraniotomi meliputi pembukaan tengkorak dengan dengan membuat flap tulang dengan mengangkat potongan sirkular tulang melalui trepanasi. Prosedur ini menurunkan angka kematian dari 72 sampai $25 \% .^{5}$

Meski demikian, pasien-pasien tetap menunjukkan kecacatan yang nyata sesudah menyelesaikan terapi, tingkat kecacatan tergantung pada beratnya kecelakaan, kerusakan organ dan umur pasien. Kecacatan yang timbul bisa berupa cacat fisik, mental, dan/atau perilaku. Trauma bisa juga mempengaruhi persepsi, kesadaran dan kognisi. Beberapa pasien menderita disfungsi fisik dan/atau mental. Perasaan marah, ketidak sabaran, depresi, kehilangan kontrol, dan gangguan tidur bisa dialami oleh pasien. Demikian juga, kontak sosial dapat berkurang akibat stress post-traumatik, dan kehidupan profesional dan personal menjadi kurang efektif.,

\section{METODE PENELITIAN}

Penelitian ini bersifat deskriptif dengan pendekatan cross sectional dengan menggunakan kuesioner tingkat kepuasan pasien cedera kepala pasca bedah di Bagian Bedah BLU RSU Prof. R.D. Kandou periode Januari 2012-Desember 2013.

\section{HASIL PENELITIAN DAN BAHASAN}

Penelitian ini menggunakan kuesioner yang terdiri dari 36 pertanyaan yang berhubungan dengan seberapa puaskah pasien mengenai apa yang mereka alami atau lakukan dalam kehidupan keseharian. Dalam penelitian ini, kami mewawancarai secara langsung 31 pasien pasien cedera kepala pasca operasi yang berhasil ditemukan dari alamat dan nomor telepon dalamcatatan medik pasien.

Tabel 1 menunjukkan responden yang banyak laki-laki, sesuai dengan data pada SMF Bedah RSUP Prof R.D. Kandou yang menunjukkan pasien cedera kepala terbanyak yang menjalani operasi, dengan usia terbanyak ialah 11-20 tahun (48,6\%). Angka ini berhubungan erat dengan tingginya angka kecelakaan kendaraan bermotor yang paling banyak melibatkan laki-laki dan mereka dengan usia remaja. Menurut Riset Kesehatan Dasar 2013, kecelakaan kendaraan bermotor paling sering terjadi pada pria (44,6 \%) dengan kelompok umur paling sering terjadinya kecelakaan adalah 15-24 tahun (64,7 \%) dan area perkotaan dengan kepadatan lalulintas yang tinggi. ${ }^{8}$

Berdasarkan distribusi GCS saat pasien masuk, paling banyak adalah cedera kepala sedang sebanyak 23 pasien (74,2\%). Dalam 
mempertimbangkan penggunaan GCS saat awal masuk sebagai prediktor prognosis, masalah yang dihadapi adalah seberapa tepat penilaian GCS saat awal masuk, bahkan prognosisnya tidak dapat diprediksi secara akurat walaupun GCS awal masuk rendah.

Keadaan akhir pasien (GOS), good recovery sebesar 58,1 \%, sedangkan moderate dissability sebesar 41,9\%. Pemulihan baik lebih besar daripada cacat ringan dan bervariasi pada setiap individu.
Sedangkan hubungan antara skor awal GCS dan GOS pada skor awal GCS, pasien dengan GCS ringan, moderate dissability dan good recovery masing-masing 1 pasien (3,2 \%). Pasien dengan GCS sedang paling banyak good recovery (48,4 \%). Pasien dengan GCS berat, paling banyak mengalami moderate dissability (12,9\%). Pada cross tabulasi antara GCS dan GOS, terlihat bahwa GCS yang rendah berhubungan dengan tingginya kecacatan yang dialami.

Tabel 1. Karakteristik umum responden

\begin{tabular}{llll}
\hline Jenis kelamin & Laki-laki & 19 & $61,3 \%$ \\
& Perempuan & 12 & $38,7 \%$ \\
& Jumlah & $\mathbf{3 1}$ & $\mathbf{1 0 0} \%$ \\
\hline Usia & $<10$ tahun & 1 & $3,2 \%$ \\
& $11-20$ tahun & 15 & $48,6 \%$ \\
$21-30$ tahun & 6 & $19,4 \%$ \\
31-40 tahun & 3 & $9,7 \%$ \\
& $41-50$ tahun & 2 & $6,5 \%$ \\
51-60 tahun & 1 & $3,2 \%$ \\
61-70 tahun & 2 & $6,5 \%$ \\
& $>71$ tahun & 1 & $3,2 \%$ \\
Jlamat & Jumlah & $\mathbf{3 1}$ & $\mathbf{1 0 0} \%$ \\
\hline & Bahu & 1 & $3,2 \%$ \\
& Lanjer & 1 & $3,2 \%$ \\
& Malalayang & 2 & $6,5 \%$ \\
& Manado & 6 & $19,4 \%$ \\
Mapanget & 3 & $9,7 \%$ \\
Molas & 2 & $6,5 \%$ \\
& Ranomuut & 1 & $3,2 \%$ \\
Sario & 1 & $3,2 \%$ \\
& Sea & 3 & $9,7 \%$ \\
Singkil & 3 & $9,7 \%$ \\
Teling & 1 & $3,2 \%$ \\
Tuminting & 1 & $3,2 \%$ \\
Wanea & 5 & $16,6 \%$ \\
Total & 1 & $3,2 \%$ \\
& & $\mathbf{3 1}$ & $\mathbf{1 0 0} \%$ \\
\hline & &
\end{tabular}

Tabel 2. Distribusi penderita cedera kepala berdasarkan keadaan awal pasien (GCS)

\begin{tabular}{lcc}
\hline $\begin{array}{l}\text { Keadaan awal } \\
\text { (GCS) }\end{array}$ & Frekuensi & $\%$ \\
\hline Ringan & 2 & 6,5 \\
$\begin{array}{lc}(14-15) \\
\text { Sedang (9-13) }\end{array}$ & 23 & 74,2 \\
Berat (3-8) & 6 & 19,3 \\
\hline Total & 31 & 100 \\
\hline
\end{tabular}

Tabel 3. Distribusi penderita cedera kepala berdasarkan keadaan akhir pasien (GOS)

\begin{tabular}{lcc}
\hline $\begin{array}{l}\text { Keadaan akhir } \\
\text { (GOS) }\end{array}$ & Frekuensi & $\%$ \\
\hline Dead & 0 & 0 \\
Moderate disability & 13 & 41,9 \\
Good recovery & 18 & 58,1 \\
\hline Total & 37 & 100 \\
\hline
\end{tabular}


Zwingly, Oley, Limpeleh: Gambaran kualitas hidup pasien cedera kepala ...

Tabel 4. Hubungan antara skor awal GCS dan GOS

\begin{tabular}{rrrrr}
\hline Skor awal & & & GOS & \multirow{2}{*}{ Total } \\
\cline { 2 - 4 } GCS & Dead & Moderate dissability & Good recovery & \\
\hline Ringan & $0(0 \%)$ & $1(3,2 \%)$ & $1(3,2 \%)$ & $2(6.5 \%)$ \\
Sedang & $0(0 \%)$ & $8(25,8 \%)$ & $15(48,4 \%)$ & $23(74,2 \%)$ \\
Berat & $0(0 \%)$ & $4(12,9 \%)$ & $2(6,5 \%)$ & $6(19,3 \%)$ \\
\hline Total & $0(0 \%)$ & $13(41,9 \%)$ & $18(58,1 \%)$ & $31(100 \%)$ \\
\hline
\end{tabular}

Tabel 5. Karakteristik responden tentang kepuasan

\begin{tabular}{ccc}
\hline Kepuasan & Frekuensi & $\mathbf{\%}$ \\
\hline Puas & 17 & 54,8 \\
Tidak puas & 14 & 45,2 \\
\hline Total & $\mathbf{3 1}$ & $\mathbf{1 0 0}$ \\
\hline
\end{tabular}

Tabel 6. Hubungan antara kepuasan dan GOS

\begin{tabular}{lcccc}
\hline Tingkat & \multicolumn{3}{c}{ GOS } & \multirow{2}{*}{ Total } \\
\cline { 2 - 4 } kepuasan & Dead & Moderate dissability & Good recovery & \\
\hline Puas & $0(0 \%)$ & $6(19,4 \%)$ & $11(35,5 \%)$ & $17(54.8 \%)$ \\
Tidak puas & $0(0 \%)$ & $9(29,0 \%)$ & $5(16,1 \%)$ & $14(45,2 \%)$ \\
\hline
\end{tabular}

\section{SIMPULAN}

Berdasarkan hasil penelitian kualitas hidup pada pasien cedera kepala pasca operasi maka dapat disimpulkan bahwa:

1. GCS yang rendah berhubungan dengan tingginya kecacatan yang dialami.

2. Sebagian besar responden merasa puas terhadap kualitas hidup mereka setelah cedera kepala pasca operasi, namun sebagian tidak merasa puas dengan kualitas hidupnya

3. Ketidakpuasan pasien terletak pada bidang-bidang kehidupan yang penting, termasuk kesehatan dan fungsinya, dalam hal psikologis/ spiritual, sosial dan ekonomi serta dukungan keluarga.

\section{SARAN}

1. Rehabilitasi pasien cedera kepala pasca operasi sangat penting terutama mereka dengan cacat fisik atau mental agar mereka bisa berada dalam lingkungan mereka dengan normal.

2. Follow-up pasien-pasien pasien cedera kepala pasca operasi perlu dilakukan dengan cara kontrol kembali untuk melihat semua perubahan fisik atau mental yang terjadi agar mudah ditangani kembali.

\section{DAFTAR PUSTAKA}

1. Rosenfeld JV, Maas AI, Bragge P, Morganti-Kossmann MC, Manley GT, Gruen RL. Early Management of severe traumatic brain injury. Lancet. 2012 September: p. 1088-95.

2. Antara News. [Online].; 2012 [cited 2014 September 26. Available from: http://www.antarasulut.com/print/18140 /kecelakaan-lalu-lintas-di-sulut-turun37-persen.com

3. Dawodu ST, Campagnolo DL. Traumatic Brain Injury (TBI) - Definition, Epidemiology, Pathophysiology. Medscape Refference. 2013 Mar.

4. Levine JM, Kumar MA. Traumatic brain injury. Neurocritical Care Society Practice Update, 2013.

5. Maas AI, Stocchetti N, Bullock R. Moderate and severe traumatic brain injury in adult. Lancet Neurol. 2008: p. 728-41.

6. Chaikoolvatana A, Sripech S. Quality of life of road accident head injury patient after craniotomy. Southeast Asian J 
Jurnal e-Clinic (eCl), Volume 3, Nomor 1, Januari-April 2015

Trop Med Public Health. 2012; 38(4): p. 761-8.

7. Brunicardi CF, Andersen DK, Billiar TR, Dunn DL, Hunter JG, Pollock RE. Trauma. In Schwartz's Principles of surgery: McGraw Hill's Access
Medicine, 2007.

8. RISKESDAS. Riset Kesehatan Dasar. , Badan Penelitian dan Pengembangan Kesehatan Kementerian Kesehatan RI Tahun 2013; 2013. 